\title{
Personel Seçimi için Gri Sistem Teori Tabanlı Bütünleşik Bir Yaklaşım
}

\author{
An Integrated Approach Based on Grey System Theory for Personnel Selection
}

Erkan KÖSE ${ }^{1}$, Hakan Soner APLAK ${ }^{2}$, Mehmet KABAK ${ }^{3}$

\begin{abstract}
ÖZET
Gri llişkisel Analiz (GiA) belirli bir sistem içerisinde iki eleman ya da iki alt sistem arasında değişen ilişkinin ölçümünü ifade eder. GİA' de iki faktör arasındaki ilişkinin derecesi, faktörlerin sergilemiş oldukları seyirlerin geometrik olarak karşılaştııılması ile elde edilir. Faktörlerin sergilemiş oldukları seyir geometrik olarak birbirine ne kadar çok benzerse aradaki ilişkinin o denli güçlü olduğundan bahsedilir. Bu çalışmada hem sübjektif hem de objektif kriterlerin yer aldığı grup karar verme problemlerinin çözümü için GíA ve Gri Analitik Ağ Süreci (GANP) bütünleşik olarak kullanılmıştır. Örnek uygulama olarak eğitim hizmetleri sağlayan bir kurum için personel seçim problemi ele alınmıştır. Elde edilen sonuçlar Gía' in personel seçim problemlerinin çözümü aşamasında başarı ile uygulanabileceğini göstermiştir.
\end{abstract}

Anahtar kelimeler: Gri ilişkisel analiz, gri analitik ağ süreci, çok kriterli karar verme, personel seçimi.

\section{Gíriş}

Disiplinler arası bir yaklaşım olan gri sistem teorisi ilk olarak 1980'li yılların başında Deng (1982) tarafından ortaya atılmıştır. Gri sistem teorisi belirsizliğin sayılaştırılmasında alternatif bir metottur. Ortaya çıkışındaki temel düşünce stokastik veya bulanık yöntemlerle üstesinden gelinemeyen belirsiz sistemlerin davranışlarını, sınırlı sayıda veri yardımı ile tahmin etmektir (Liu ve Lin, 2006).

Gri sistem teorisinin başlıca görevlerinden bir tanesi gözlem verilerine dayanarak sistemde yer alan faktörler arasındaki matematiksel ilişkiyi ortaya çıkarmaktır. Analiz edilen elemanlar arasındaki benzerlikler ya da farklılıklar "gri ilişki" olarak isimlendirilir.

Gri Ilişkisel Analiz (GIA) faktörler arasında karmaşık ilişkilerin yer aldığı problemler için uygun bir çözüm yöntemidir. Bu özelliği nedeniyle literatürde Çok Kriterli Karar Verme (ÇKKV) problemlerinin çözümünde tek başına veya diğer yöntemlerle bütünleşik olarak sıkça kullanıldığı görülmektedir. Yeh ve Lu (2000) silah sistemlerinin seçiminde, Chen ve

\begin{abstract}
Grey Relational Analysis (GIA) means measurement of variable relationship between two elements in a system ortwosubsystems. There lational grade between two factors in GIA is obtained by comparing geometrical pattern's of factors. It is mentioned that the more thepatterns displayed by factors similar to each other thes tronger there lationship between factors are. In this study GIA and Grey Analytic Network Process (GANP) are used integral lytosolve group decision making problems in which both subjective and objective criteria are taking place. As a case study personnel selection problem of an education institution is handled. Out comes show that GIA can be used successfully in the process of solving personnel selection problems.
\end{abstract}

Keywords: Greyrelation alanalysis, grey analytic network process, multi criteria decision making, personnel selection.

Tzen (2004) mülteciler için ev sahibi ülkenin seçiminde, Song ve arkadaşları (2005) yazılım projelerinin değerlendirilmesinde GiA kullanmışlardır. Wu (2002), TOPSIS ve OCRA yöntemleri ile Gİ'yı karşılaştırmış ve ÇKKV problemlerinin çözümü için tek bir metoda bağlı kalmak yerine birden fazla metot kullanılmasını tavsiye etmiştir. Song ve Jamalipour (2005) servis kalitesi açısından dinamik ortamda en iyi mobil ağın seçiminde Analitik Hiyerarşi Süreci (AHP) ile birlikte, Jadidi ve arkadaşları ise (2008) tedarikçi seçiminde TOPSis yöntemi ile birlikte GIA kullanmışlardır. Zhang ve Liu (2011), Pramanik ve Mukhopadhyaya (2011) personel seçim problemi için GíA ile sezgisel bulanık mantık tabanlı bütünleşik bir yaklaşım önerirken Goyal ve Grover (2012) ileri üretim sistemlerinin seçiminde bulanık mantık tabanlı GiA önermişlerdir. Wu ve Luyan (2012) yatırım kararlarının verilmesinde AHP ile birlikte GIA'dan faydalanmışlardır.

Bu çalışmada eğitim hizmetleri sağlayan bir kurum için personel seçim problemi ele alınmıştır. Çalışmada ele alınan kurumda personel seçimi dört kişilik uzman ekip tarafından gerçekleştirilmektedir. Adaylar her 
bir uzman tarafından daha önceden belirlenen sekiz farklı kritere göre değerlendirilmektedir. Problem bu hali ile hem sübjektif hem de objektif kriterlerin yer aldığı grup karar verme problemidir.

Literatürde personel seçimi için ÇKKV yöntemleriyle yapılmış çok sayıda çalışma bulunmaktadır. KelemenisandAskounis (2010) personel seçimi için TOPSIS tabanlı yeni bir çalışma önermiş, bulanık TOPSIS yöntemini veto eşik değerleriyle kullanmışlardır. Dursun ve Karsak (2010) TOPSIS yöntemi ve iki öğeli dilsel temsil modelini kullanarak personel seçimine yönelik bir bulanık model önermişlerdir. Lazarevic-Petrovic (2001) bulanık AHP ile, Güngör ve arkadaşları (2009) nicel ve nitel kriterleri dikkate alarak AHP ile personel değerlendirmesi yapmışlardır. Gibney ve Shang (2007) ise AHP ile dekan seçimi problemine çözüm önermişlerdir. Chen, Hwang ve Hung (2009) personel seçimi ve değerlendirmesini PROMETHEE sıralama yöntemi ile yapmıştır. Wang (2009) Ar-Ge personeli seçimi için gri teori ve TOPSIS metotlarını kullanmıştır. Çalışmada, kriter ağırlıkları ve adayların niteliklerini gösteren dilsel değişkenler gri sayılarla ifade edilmiş, sıralama gri ilişki derecelerine göre yapılmıştır. Ayub, Kabir ve Alam (2009) ise bulanık Analitik Ağ Süreci (ANP) ile personel seçimi problemine çözüm önermişlerdir. Kabak ve arkadaşları (2012) keskin nişancı seçiminde kriter ağırlıklarını ANP ile bulmuş, sıralamayı TOPSIS ve ELECTRE yöntemleriyle yapmıştır.

Çalışmada ele alınan problemin çözümü için literatürde yaygın olarak kullanılan yöntemlerden farklı olarak gri sistem teori tabanlı bütünleşik bir yaklaşım kullanıımıştır. Karar verme sürecinde kullanılan kriter ağırlıkları Gri Analitik Ağ Süreci (GANP) kullanılarak belirlenmiş daha sonra GíA kullanılarak adayların ideal noktaya olan uzaklıklarına göre sıralamaları yapılmıştır. Sonuçları test etmek maksadiyla problem TOPSiS, ANP ve ELECTRE yöntemleri kullanılarak çözülmüş ve elde edilen sonuçlar karşılaştırılmıştır. Ulaşılan sonuçlar GİA ve GANP' nin personel seçimi problemlerinin çözüm aşamasında başarı ile uygulanabileceğini göstermiştir.

GANP'de klasik ANP'den farklı olarak kriterler ve alternatifler için değerlendirme yaparken kesin değerleryerine gri sayılarkullanılmaktadır. Buyaklaşım özellikle karar vericilerin yeterli tecrübelerinin bulunmadığı ve eksik bilginin yer aldığı durumlarda problemin çözümünü kolaylaştırmaktadır. Literatürde GIA ve ANP' nin birlikte kullanıldığı çalışmalar mevcuttur (Chen ve Tzeng, 2011; Hsu, 2012). Ancak GiA ve GANP 'nin birlikte kullanıldığı herhangi bir çalışmaya rastlanmamıştır. Bu açıdan yapılan bu çalışmanın literatüre katkı sağladığı değerlendirilmektedir.

Çalışmanın bundan sonraki bölümünde gri sistem teorisi ile ilgili temel tanımlamalara yer verilmiş, GANP ve GIA konuları detaylı olarak incelenmiştir. Üçüncü bölümde eğitim hizmetleri sağlayan bir firma için personel seçim problemi örnek bir uygulama olarak ele alınmış, son bölümünde ulaşılan sonuçlar tartışılmış ve genel bir değerlendirme yapılmıştır.

\section{GRI SISTEM TEORISI}

Disiplinler arası bir yaklaşım olan gri sistem teori, küçük örneklem ve zayıf bilginin yer aldığı problemlere çözüm bulabilmek için 1980'li yılların başında Deng (1982) tarafından ortaya atılmıştır. Ortaya çıkışındaki temel düşünce stokastik veya bulanık yöntemlerle üstesinden gelinemeyen belirsiz sistemlerin davranışlarını, sınırlı sayıda veri yardımı ile tahmin etmektir. Sosyal, ekonomik, endüstriyel, tarımsal, biyolojik sistemler gibi pek çok sistem ismini ilgili olduğu alandan alır. Gri sistemler ismi ise incelenen konuya ait bilgi düzeyi esas alınarak seçilmiştir (Liu ve Lin, 2006). Gri sistem teoride, herhangi bir sisteme ilişkin tüm bilgiler biliniyorsa bu tür sistemler için beyaz sistem, hiçbir bilgi bilinmiyorsa siyah sistem, kısmen bilgi sahibi olduğumuz sistemler için de gri sistem tanımlamaları kullanılmaktadır. Siyah, gri ve beyaz sistemlerin çeşitli açılardan karşılaştırılması Tablo 1'de sunulmuştur.

Tablo 1:Siyah, Gri ve Beyaz Sistemlerin Karşılaştırılması (Liu ve Lin, 2006)

\begin{tabular}{|c|c|c|c|}
\hline & Siyah & Gri & Beyaz \\
\hline Bilgi & Bilinmiyor & Tam değil & Biliniyor \\
\hline Görünüm & Karanlık & Gri & Parlak \\
\hline Süreç & Yeni & Geçiş aşamasında & Eski \\
\hline Özellik & Keşmekeş & Kompleks & Düzenli \\
\hline Yöntem & Olumsuz & Değişken & Olumlu \\
\hline Davranış & Hoşgörü & Tolerans & Katı \\
\hline Sonuç & Sonuç yok & $\begin{array}{c}\text { Birden fazla } \\
\text { çözüm }\end{array}$ & Tek çözüm \\
\hline
\end{tabular}

Bulanık matematik ve gri sistem teori deterministik olmayan sistemler için yapılan çalışmalarda kullanılan en yaygın yöntem ve teorilerdir. Farklı tipteki belirsizliklerle uğraşmalarına rağmen bu teorilerin ortak noktası, eksik bilgi ve belirsizliğin olduğu durumlarda anlamlı ve işlevsel sonuçlar çıkarabilme gücüne sahip olmalarıdır.

Bulanık matematiğin gücü, tanımsal belirsizliğe sahip problemlere çözüm bulabilmesinde yatmaktadır. Bulanık matematik kullanılarak incelenen bütün nesneler belirgin içsellik, belirgin olmayan uzantı karakteristiğine sahiptirler. Örneğin "genç adam" bulanık bir kavramdır. Genç adam 
denildiğinde neyin kastedildiğini herkes bilir ancak tam olarak hangi yaş aralığındaki insanların bu tanımlamaya uyduğunu söylemek oldukça güçtür.

Bulanık matematikten farklı olarak gri sistem teori ile incelenen nesneler belirgin uzantı, belirgin olmayan içsellik karakteristiğine sahiptirler (Deng, 1996). Örneğin "T.C Hükümeti, ülke nüfusunu 2050 yılına kadar 90 ile 100 milyon arasında tutmayı planlıyor" ifadesindeki 90 ile 100 milyon aralığı, gerçek değeri hakkında herhangi bir bilgi sahibi olmadığımız ancak sınırları kesin olarak bilinen bir gri kavramdır.

Gri sistem teori, küçük örneklem ve zayıf bilginin yer aldığı problemlere çözüm bulabilmek için geliştirilmiştir. Gri sistemlerin karakteristik özelliklerini bulanık matematikle tam olarak açıklamak mümkün değildir. Teknik olarak söylemek gerekirse, bulanık matematik kavramsal belirsizliğe sahip problemleri, geçmiş tecrübeler yardımıyla, üyelik fonksiyonlarını kullanarak çözmeye çalışır. Herhangi bir geçmiş tecrübemizin bulunmadığı, gerekli dağılımları tesis edemediğimiz veya oldukça küçük bir örnekleme erişebildiğimiz durumlarla gri sistem teori memnuniyet verici uygulamalar yapabilme gücüne sahiptir (Liu ve Lin, 2006).

Gri sistem teori temel olarak sistemler arasındaki ilişkinin analizi, model kurulması, tahmin ve karar problemlerinde sıkça kullanılan bir yöntemdir (Wen, 2004). Gri sistem teorinin uğraş alanını gri üretim, GiA, gri modelleme, gri karar verme, gri kontrol ve gri tahmin olmak üzere altı temel başlık altında incelemek mümkündür (Kose vd., 2011).

Tüm gri sistemler gri sayılar, gri eşitlikler veya gri matrisler yardımı ile tanımlanır. Gri sayılar, gerçek değerleri tam olarak bilinemeyen ancak hangi aralıkta değer alması gerektiği bilinen sayılardır. Hem alt hem de üst sınır değerine sahip gri sayılar aralık gri sayılar olarak ifade edilir ve $\otimes \in[\underline{a}, a \bar{a}]$ şeklinde gösterilirler. Bu gösterimde $\underline{a}, \otimes$ gri sayısının alt limit değerini ā ise üst limit değerini temsil eden sabit sayılardır.

$$
\otimes_{1} \in[a, b], a<b \quad \text { ve } \otimes_{2} \in[c, d], c<d
$$

olmak üzere $\otimes_{1}$ ve $\otimes_{2}$ aralık gri sayıları arasındaki matematiksel işlemler aşağıda gösterilen kurallara göre gerçekleştirilir.

Toplama Kuralı: $\otimes_{1}+\otimes_{2} \in[a+c, b+d]$

Çıkartma Kuralı: $\otimes_{1}-\otimes_{2} \in[a-d, b-c]$

Çarpma Kuralı: $\otimes_{1} * \bigotimes_{2} \in[\min \{a c, a d, b c, b d\}, \max$ $\{a c, a d, b c, b d\}]$

Bölme Kuralı: $\otimes_{1} / \otimes_{2} \in[\min \{a / c, a / d, b / c, b / d\}$, $\max \{a / c, a / d, b / c, b / d\}]$

Skaler Çarpım Kuralı: $\otimes \in[a, b], a<b$ ve $k$ pozitif gerçek sayı olmak üzere $\otimes$ gri sayısının $k$ ile skaler çarpımı $k^{*} \otimes \in[k a, k b]$ şeklinde tanımlanır.

Gri Sayıların Durulaştırılması: $\otimes \in[a, b], a<b$ olmak üzere aralık gri sayıların durulaştırılmış değeri $\widetilde{\otimes}=a$ $a+(1-a) b, a \in[0,1]$ şeklinde hesaplanır. $a=1 / 2$ için elde edilen durulaştırma değerine, eşit ağırlıklı ortalama durulaştırması denir. Aralık gri sayılar durulaştırılırken dağılım bilgisine sahip olunmadığı durumlarda genellikle eşit ağırlıklı ortalama durulaştırma yöntemi kullanılır (Liu ve Lin, 2006).

\subsection{Gri Analitik Ağ Süreci (GANP)}

AHP 1970'lerde Profesör Thomas L. Saaty tarafından geliştirilen, birden çok kriter içeren karmaşık problemlerin çözümünde kullanılan bir karar verme yöntemidir. AHP, karar vericilerin karmaşık problemleri, problemin ana hedefi, kriterleri, alt kriterler ve alternatifleri arasındaki ilişkiyi gösteren bir hiyerarşik yapıda modellemelerine olanak verir. AHP'nin en önemli özelliği karar vericinin hem objektif hem de sübjektif düşüncelerini karar sürecine dâhil edebilmesidir. Bir diğer ifade ile AHP, bilginin, deneyimin, bireyin düşüncelerinin ve önsezilerinin mantıksal bir şekilde birleştirildiği bir yöntemdir. AHP'de problemin hiyerarşik yapıda modellenebilmesi için kriter, alt kriter ve alternatifler arasında etkileşim olmadığı, bağımsız oldukları kabul edilir (Saaty, 1985; Saaty, 2000). Ancak, çoğu karar probleminde kriterlerin kendi içerisinde veya alternatifler ve kriterler arasındaki ilişki göz ardı edilemez. Örneğin ürün seçimi probleminde fiyat ile kalite veya araç performansında motor gücü ile hız arasında ilişki olması gibi. Bu problemler, yatay seviyedeki veya daha yüksek seviyedeki elemanlarla daha düşük seviyedeki elemanlar arasındaki ilişki ve bağlılıksebebiyle hiyerarşikolarakyapılandırılamazlar. Bu sebeple, yine Saaty tarafından AHP'nin uzantısı olarak Analitik Ağ Süreci (ANP) geliştirilmiştir.

ANP'de karar verme problemi bir ağ yapısı ile modellenmekte ve modelleme aşamasındaki kriterler arasındaki bağımlılıklar ve kriter içindeki iç bağımlılıklar dikkate alınmaktadır. Bundan dolayı ANP karar verme problemlerinin daha etkin ve daha doğru bir şekilde çözülmesini sağlamaktadır (Saaty, 1996). Yukarıda da belirtildiği üzere AHP karar verme problemlerini bir hiyerarşi yapı içerisinde modellerken, ANP hiyerarşiden uzak bir ağ yapısı içerisinde modellemektedir. Bu yapılar Şekil 1 ve Şekil 2'de görülmektedir. ANP'de; problem tanımlanıp model oluşturulduktan sonra ağ yapısına göre ikili karşılaştırma matrisleri oluşturulur, karar vericilerin değerlendirmelerine göre öncelik 
vektörleri hesaplanır ve alternatifler sıralanır. ANP'in detaylarına birçok çalışmadan kolaylıkla ulaşılabilir (Mohanty vd., 2005; Jharkharia ve Shankar, 2007; Onut vd., 2009; Kabak vd., 2012). Bütünleşik yöntem sunan bazı çalışmalarda ise ANP sadece kriter ağırlıklarının hesaplanmasında kullanılır, alternatifler TOPSIS, PROMETHEE vb. diğer ÇKKV yöntemleriyle değerlendirilir.

Karar vericiler kriterler veya alternatifler için değerlendirme yaparken her zaman kesin bilgilere sahip olmayabilir. Bu durumlarda gri teori tabanlı yaklaşımlar başarıyla uygulanabilir (ZhangandLiu, 2011). GANP'de klasik ANP'den farklı olarak bu muğlaklıktan dolayı ikili karşılaştırma matrislerinde karar vericiler tarafından Tablo 2'de verilen gri sayılar kullanılır (Li vd., 2007; Mohammad vd., 2011).

Tablo 2: Kriter Ağırlıkları için Ölçek

\begin{tabular}{|l|c|c|}
\hline Dilsel Ifade & Gri Sayı & Gri Karşılık Sayı \\
\hline Eşit derecede önemli & {$[1,1]$} & {$[1,1]$} \\
\hline Zayıf derecede önemli & {$[1,3]$} & {$[1 / 3,1]$} \\
\hline Kuvvetli derecede önemli & {$[3,5]$} & {$[1 / 5,1 / 3]$} \\
\hline Çok kuvvetli derecede önemli & {$[5,7]$} & {$[1 / 7,1 / 5]$} \\
\hline Aşırı derecede önemli & {$[7,9]$} & {$[1 / 9,1 / 7]$} \\
\hline
\end{tabular}

\section{Bir ikili karşılaştırma matrisi}

$\left(\otimes a_{i j}=\left[a_{i j}, a_{i j}\right] ; i=1,2,3, \ldots, m ; j=1,2,3, \ldots, n\right)$ gibi gri sayılarī kullanarak aşağıdaki gibi oluşturulur (Onut vd., 2009):

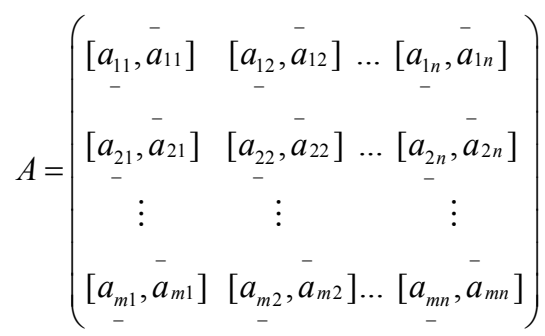

$a_{m n}$ değeri satırdaki $m$ elemanı ile sütundaki $n$ elemanının karşılaştırılması sonucu varılan kararı gösterir. GANP kriter ağılıklarının bulunması ve alternatiflerin sıralanması için kullanılabilir. Bu çalışmada GANP kriter ağırlıklarının hesaplanması için kullanılacak, alternatiflerin sıralanması GIA ile yapılacaktır.

\subsection{Gri ilişkisel Analizi}

Gri ilişki belirli bir sistem içerisinde iki eleman ya da iki alt sistem arasında değişen ilişkinin ölçümünü ifade etmektedir (Feng ve Wang, 2000). Analiz edilen elemanlar arasındaki benzerlikler ya da farklılıklar "gri ilişki" olarak isimlendirilmektedir.

GiA iki farklı sistem veya aynı sistemde yer alan iki eleman arasındaki zamanla değişen ilişkilerin ölçümünü sağlayan güçlü bir metottur. Sınırlandırılmış gri ilişki derecesi ve global gri ilişki derecesi olmak üzere iki farklı yöntemi vardır. Illk yöntemde referans seri verilir ve referans seriden olan uzaklıklara göre diğer serilerin sıralaması yapılır. İkincisinde ise her seri referans seri olabilir ve öz vektör yöntemi kullanılarak serilerin sıralaması yapılır (Wen, 2004).

Sosyal, ekonomik, ekolojik, eğitim ve benzeri soyut sistemler bir çok faktörü içinde barındırmaktadır. Bu faktörler arasındaki bazı karşılıklı ilişkiler sistemin

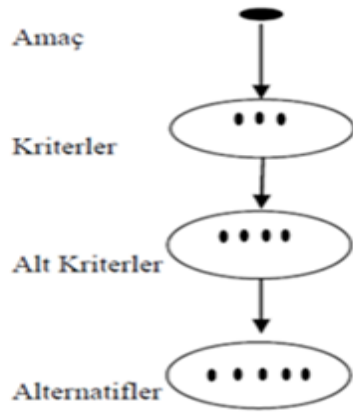

Șekil 1: Hiyerarşik Yap1

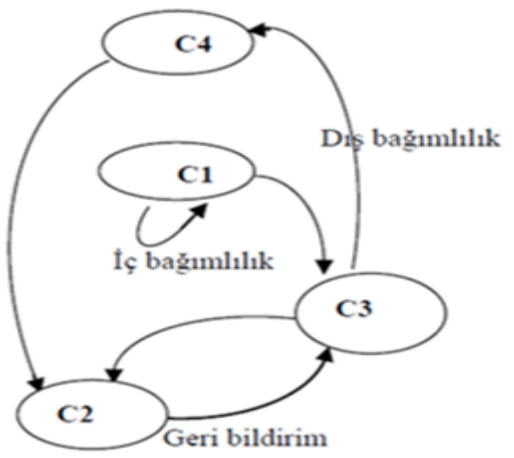

Şekil 2: Ağ yap1s1 
gelişimi ve yönelimini belirler. Karar vericiler genellikle aşağıdaki sorulara cevap bulabilmek için bu faktörlerle ilgilenirler (Liu ve Lin, 2006):

-Pek çok faktör/kriter arasından hangileri diğerlerine oranla daha önemlidir?

- Sistemin gelişimi açısından hangi faktörler diğerlerinden daha etkilidir?

- Sistem içerisindeki hangi faktörler desteklenmelidir ki istenilen yönde değişim sağlanabilsin?

- Sistem içerisindeki hangi faktörler kontrol altında tutulmalıdır ki istenilen yönde değişime mani olamasınlar?

İstatistik bilim dalı içerisinde yer alan regresyon analizi, varyans analizi, temel bileşenler analizi gibi teknikler bu sorulara cevap bulabilmek için geliştirilmiş yöntemlerdir. Ancak bu yöntemler aşağıda sıralanan dezavantajlara sahiptirler (Liu ve Lin, 2006):

- Büyük miktarda veriye ihtiyaç vardır. Aksi takdirde istatistiksel olarak güvenilir sonuçlar elde etmek oldukça zordur.

- Elde edilen veriler bilinen bazı dağılımlara uygun olmalıdır.

- Oldukça uzun ve karmaşık matematiksel işlemlere gereksinim duyulmaktadır.

- Genellikle nitel araştırma sonuçları nicel analizlerle farklı sonuçlar üretir ve bu durum incelen sistemin farklı algılanmasına neden olur.

Pek çok faktör ve az sayıda verinin bulunduğu durumlarda, iki süreç arasındaki korelasyonun ortaya çıkartılmasında veri yetersizliği nedeni ile istatistiksel tabanlı regresyon analiz yöntemleri sağlıklı sonuçlar üretemez. İşte bu gibi durumlar Gi $A^{\prime}$ in gücünü gösterebildiği en uygun ortamlardır.

Gi'A' de iki faktör arasındaki ilişkinin derecesi, faktörlerin sergilemiş oldukları seyirlerin geometrik olarak karşılaştırılması ile elde edilir. Faktörlerin sergilemiş oldukları seyir geometrik olarak birbirine ne kadar çok benzerse aradaki ilişkinin o denli güçlü olduğundan bahsedilir.

Gi $A^{\prime}$ in uygulama adımları aşağıda detaylı olarak açıklanmıştır (Liu ve Lin, 2006).

Adım 1: Referans serinin oluşturulması

Referans seri mevcut alternatiflerin her bir kriter için aldıkları en yüksek (maliyet türü kriterler için en düşük) değerlerden veya kriterler için daha önceden belirlenmiş ideal değerlerden oluşur. Örneğin "yabancı dil notu" şeklinde tanımlanan bir kriterin referans serideki değeri ya mevcut alternatifler arasından en yüksek yabancı dil notuna karşılık gelir ya da o sınav türü için ideal not olan 100 tam puan şeklinde belirlenir. $\mathrm{n}$ adet kriterin değerlendirildiği bir problem için referans seri aşağıdaki gibi gösterilir.

$$
\chi_{0}=\left(\chi_{0}(1), \chi_{0}(2), \chi_{0}(3), \ldots \ldots \ldots, \chi_{0}(n)\right)
$$

Adım 2: Verilerin normalize edilmesi

Verilerin normalizasyonu farklı ölçü birimlerine sahip verilerin yer aldığı seriler arasında karşılaştırma yapabilmek için gereklidir. Ham veri setleri $X_{i}^{0}(k)$ ile gösterilmek üzere $X_{i}(k)$ normalize değerleri üç farklı duruma göre hesaplanır.

Daha büyük daha iyi durumunda normalizasyon:

$$
\begin{aligned}
& \chi_{i}(k)=\frac{\chi_{i}^{0}(k)-\min \chi_{i}^{0}(k)}{\max \chi_{i}^{0}(k)-\min \chi_{i}^{0}(k)} \\
& i=1, \ldots \ldots m ; k=1, \ldots . . n
\end{aligned}
$$

Daha düşük daha iyi durumunda normalizasyon:

$$
\begin{aligned}
& \chi_{i}(k)=\frac{\max \chi_{i}^{0}(k)-\chi_{i}^{0}(k)}{\max \chi_{i}^{0}(k)-\min \chi_{i}^{0}(k)} \\
& \mathrm{i}=1, \ldots . . \mathrm{m} ; \mathrm{k}=1, \ldots . . \mathrm{n}
\end{aligned}
$$

İdeal değer daha iyi durumunda normalizasyon:

$$
\begin{aligned}
& \chi_{i}(k)=1-\frac{\left|\chi_{i}^{0}(k)-\chi^{0}\right|}{\max \chi_{i}^{0}(k)-\chi^{0}} \\
& \mathrm{i}=1, \ldots . . \mathrm{m} ; \mathrm{k}=1, \ldots . . \mathrm{n}
\end{aligned}
$$

Adım 3: Gri ilişki katsayılarının hesaplanması

$$
\begin{aligned}
& \varepsilon\left(\chi_{0}(k), \chi_{i}(k)\right)=\frac{\Delta_{\min }+\xi \Delta_{\max }}{\Delta_{o i}(k)+\xi \Delta_{\max }} \\
& \mathrm{i}=1, \ldots . \mathrm{m} ; \mathrm{k}=1, \ldots . . \mathrm{n} \\
& \Delta_{0 i}(k)=\left|X_{0}(k)-X_{i}(k)\right| \\
& \mathrm{i}=1, \ldots . \mathrm{m} ; \mathrm{k}=1, \ldots . . \mathrm{n} \\
& \Delta_{\min }=\min _{i} \min _{k}\left|X_{0}(k)-X_{i}(k)\right| \\
& \mathrm{i}=1, \ldots . . \mathrm{m} ; \mathrm{k}=1, \ldots . . \mathrm{n}
\end{aligned}
$$

$$
\begin{aligned}
& \Delta_{\text {max }}=\max _{i} \max _{k}\left|X_{0}(k)-X_{i}(k)\right| \\
& \mathrm{i}=1, \ldots . \mathrm{m} ; \mathrm{k}=1, \ldots . . \mathrm{n}
\end{aligned}
$$

Eşitlik (6)' daki $\Delta_{0 i}(k)$ ifadesi normalize edilmiş değerler için referans seri ile karşılaştırılan seri arasındaki farkı ifade etmektedir. $\xi \in(0,1)$ ise $\Delta_{\min }$ ile $\Delta_{\max }$ arasındaki çözünürlüğü ayarlamakta kullanılan bir katsayıdır ve genellikle 0,5 alınır.

Adım 4: Gri ilişki derecelerinin hesaplanması 


$$
\gamma\left(\chi_{0}, \chi_{i}\right)=\frac{1}{n} \sum_{k=1}^{n} \varepsilon\left(\chi_{o}(k), \chi_{i}(k)\right)
$$

Gri ilişki derecesi referans seri ile karşılaştırılan serinin benzerlik derecesini gösteren bir ölçüttür. Diğer bir deyişle şayet $\gamma\left(X_{d} X_{2}\right)>\gamma\left(X_{\sigma^{\prime}} X_{1}\right)$ ise $X_{2}$ serisi geometrik olarak $X_{1}$ serisine oranla referans seriye daha benzer özelliklere sahip bir seridir denir.

Şayet kriterler farklı ağırlık değerlerine sahipse bu durumda gri ilişki derecesi kriter ağırlıkları ile gri ilişki katsayıları çarpılarak hesaplanır.

$$
\gamma\left(\chi_{0}, \chi_{i}\right)=\sum_{k=1}^{n} \varepsilon\left(\chi_{o}(k), \chi_{i}(k)\right) \cdot W_{i}(k)
$$

\section{UYGULAMA}

Bu çalışmada eğitim hizmetleri sağlayan bir kurum için personel seçim problemi ele alınmıştır. Çaış̧mada ele alınan kurumda personel seçimi insan kaynakları bölümünde görevli dört kişilik uzman ekip tarafından $\left(D_{1}, D_{2^{\prime}}, D_{3^{\prime}}, D_{4}\right)$ gerçekleştirilmektedir. Söz konusu ekip kararlarını toplu karar verme tekniği ile almaktadır. Adaylar $\left(\mathrm{A}_{1}, \mathrm{~A}_{2}, \mathrm{~A}_{3}, \mathrm{~A}_{4}, \mathrm{~A}_{5}\right)$ daha önceden kurum tarafından belirlenen sekiz farklı kritere göre $\left(C_{1}, C_{2^{\prime}}, C_{3^{\prime}}, C_{4^{\prime}} C_{5^{\prime}}, C_{6^{\prime}}, C_{7}, C_{8}\right)$ değerlendirilmektedir. Adayların değerlendirmesinde kullanılan kriterler ve bu kriterlere ilişkin açıklamalar Tablo 3'de gösterilmiştir.

Tablo 3: Adayların Değerlendirmesinde Kullanılan Kriterler ve Açıklamala

\begin{tabular}{|l|l|l|}
\hline & \multicolumn{1}{|c|}{ Kriter Adı } & \multicolumn{1}{c|}{ Açıklama } \\
\hline$C_{1}$ & $\begin{array}{l}\text { Anlama ve } \\
\text { Anlatma Yeteneği }\end{array}$ & $\begin{array}{l}\text { Adayların anlatım ve iletişim becerilerine ilişkin } \\
\text { sübjektif değerlendirmelerdir. }\end{array}$ \\
\hline$C_{2}$ & Görev Bilinci & $\begin{array}{l}\text { Adayların sorumluluk alma, aldığı görevi yerine } \\
\text { getirme konularında sahip oldukları yeteneklere } \\
\text { ilişkin sübjektif değerlendirmelerdir. }\end{array}$ \\
\hline$C_{3}$ & $\begin{array}{l}\text { Sosyal Uyum } \\
\text { (Birlikte çalışa- } \\
\text { bilme) }\end{array}$ & $\begin{array}{l}\text { Adayların grup içerisinde uyumlu çalışabilme } \\
\text { yeteneklerine ilişkin sübjektif değerlendirme- } \\
\text { lerdir. }\end{array}$ \\
\hline$C_{4}$ & $\begin{array}{l}\text { Rol Model Olması } \\
\text { Adayların örnek olma, model teşkil etme yete- } \\
\text { neklerine ilişkin sübjektif değerlendirmelerdir. }\end{array}$ \\
\hline$C_{5}$ & $\begin{array}{l}\text { Öğretmenlik } \\
\text { Deneyimi } \\
\text { (İş tecrübesi) }\end{array}$ & $\begin{array}{l}\text { Adayların yıl bazında geçmiş iş tecrübelerini } \\
\text { gösteren objektif değerlendirmelerdir. }\end{array}$ \\
\hline$C_{6}$ & $\begin{array}{l}\text { Bilimsel Yeterlilik } \\
\text { adayların eğitim kurumu tarafından yapılan } \\
\text { bilimsel yeterlilik sınavından aldığı notu göster- } \\
\text { mektedir. }\end{array}$ \\
\hline$C_{7}$ & $\begin{array}{l}\text { Yabancı Dil Bilgisi } \\
\text { Cokayların eğitim kurumu tarafından yapılan ya- } \\
\text { bancı dil sınavından aldığı notu göstermektedir. }\end{array}$ \\
\hline Çalışmaları & $\begin{array}{l}\text { Adayların bilimsel dergi ve kongrelerde yayın- } \\
\text { lanmış çalışmaları için kurum tarafından oluştu- } \\
\text { rulan dönüşüm tablosu kullanılarak hesaplanan } \\
\text { akademik yayın puanıdır. }\end{array}$ \\
\hline
\end{tabular}

Problem bu hali ile hem sübjektif hem de objektif kriterlerin yer aldığı grup karar verme problemidir. Karar vericilerden her bir adayı $C_{1}, C_{2}, C_{3}$ ve $C_{4}$ subjektifkriterlerine göre değerlendirmeleri istenmiştir. Adayların subjektif kriterlere değerlendirmesinde kullanılan skala ve gri sayı karşılıkları Tablo 4'de, karar vericiler tarafından her bir adaylar için yapılan değerlendirmeler ise Tablo 5'de sunulmuştur.

Tablo 4: Sübjektif Kriter için Değerlendirme Skalası (Li vd., 2007; Mohammad vd., 2011)

\begin{tabular}{|l|c|}
\hline \multicolumn{1}{|c|}{ Değerlendirme } & Gri Sayı Karşı̆ı̆̆ı \\
\hline Çok Zayıf (VP) & {$[0,10]$} \\
\hline Zayıf (P) & {$[10,30]$} \\
\hline Orta Derecede Zayıf (MP) & {$[30,40]$} \\
\hline Ortalama (F) & {$[40,50]$} \\
\hline Orta Derecede lyi (MG) & {$[50,60]$} \\
\hline İyi (G) & {$[60,90]$} \\
\hline Çok İyi (VG) & {$[90,100]$} \\
\hline
\end{tabular}

Tablo 5: Adayların Subjektif Kriterlere

\begin{tabular}{|c|c|c|c|c|c|c|}
\hline & & $A_{1}$ & $\mathrm{~A}_{2}$ & $\mathrm{~A}_{3}$ & $\mathrm{~A}_{4}$ & $A_{5}$ \\
\hline \multirow{4}{*}{$C_{1}$} & $\mathrm{D}_{1}$ & VG & G & G & G & G \\
\hline & $\mathrm{D}_{2}$ & MG & $\mathrm{G}$ & MG & VG & G \\
\hline & $\mathrm{D}_{3}$ & G & G & G & VG & G \\
\hline & $\mathrm{D}_{4}$ & VG & VG & G & VG & G \\
\hline \multirow{4}{*}{$C_{2}$} & $\mathrm{D}_{1}$ & G & VG & $\mathrm{F}$ & MG & $\mathrm{F}$ \\
\hline & $\mathrm{D}_{2}$ & G & MG & MG & MG & MG \\
\hline & $\mathrm{D}_{3}$ & G & VG & G & MG & G \\
\hline & $\mathrm{D}_{4}$ & VG & VG & $\mathrm{F}$ & MG & $\mathrm{F}$ \\
\hline \multirow{4}{*}{$C_{3}$} & $\mathrm{D}_{1}$ & $\mathrm{~F}$ & $\mathrm{G}$ & VG & G & VG \\
\hline & $\mathrm{D}_{2}$ & MG & G & VG & G & VG \\
\hline & $\mathrm{D}_{3}$ & G & $\mathrm{F}$ & G & G & VG \\
\hline & $\mathrm{D}_{4}$ & MG & MG & G & G & VG \\
\hline \multirow{4}{*}{$C_{4}$} & $\mathrm{D}_{1}$ & VG & VG & MG & G & G \\
\hline & $\mathrm{D}_{2}$ & VG & $\mathrm{G}$ & MG & VG & G \\
\hline & $\mathrm{D}_{3}$ & G & MG & $\mathrm{F}$ & VG & MG \\
\hline & $\mathrm{D}_{4}$ & G & $\mathrm{G}$ & G & VG & G \\
\hline
\end{tabular}
Göre Değerlendirmesi

Tablo 5'deki subjektif değerlendirmelerin gri sayı karşılıkları Tablo 6'da gösterilmiştir. 
Tablo 6: Subjektif Değerlendirmelerin Gri Sayı Karşılıkları

\begin{tabular}{|c|c|c|c|c|c|c|c|c|c|c|c|}
\hline & & & $A_{1}$ & & & & $A_{3}$ & & $\mathrm{~A}_{4}$ & & $A_{5}$ \\
\hline \multirow{4}{*}{$C_{1}$} & $D_{1}$ & [90 & 100] & {$[60$} & 90] & {$[60$} & 90] & {$[60$} & 90] & {$[60$} & 90] \\
\hline & $D_{2}$ & {$[50$} & 60] & {$[60$} & 90] & {$[50$} & 60] & {$[90$} & $100]$ & {$[60$} & 90] \\
\hline & $\mathrm{D}_{3}$ & {$[60$} & 90] & {$[60$} & 90] & {$[60$} & 90] & [90 & $100]$ & {$[60$} & $90]$ \\
\hline & $\mathrm{D}_{4}$ & {$[90$} & 100] & {$[90$} & 100] & {$[60$} & 90] & {$[90$} & 100] & {$[60$} & 90] \\
\hline \multirow{4}{*}{$C_{2}$} & $\mathrm{D}_{1}$ & {$[60$} & 90] & [90 & $100]$ & {$[40$} & 50] & {$[50$} & 60] & {$[40$} & $50]$ \\
\hline & $D_{2}$ & {$[60$} & 90] & {$[50$} & 60] & {$[50$} & 60] & {$[50$} & 60] & {$[50$} & $60]$ \\
\hline & $D_{3}$ & {$[60$} & 90] & {$[90$} & 100] & {$[60$} & 90] & {$[50$} & 60] & {$[40$} & 50] \\
\hline & $D_{4}$ & {$[90$} & 100] & {$[90$} & 100] & {$[40$} & 50] & {$[50$} & 60] & {$[40$} & 50] \\
\hline \multirow{4}{*}{$C_{3}$} & $\mathrm{D}_{1}$ & {$[40$} & 50] & {$[60$} & 90] & {$[90$} & 100] & {$[60$} & 90] & {$[90$} & 100] \\
\hline & $D_{2}$ & {$[50$} & 60] & {$[60$} & $90]$ & {$[90$} & 100] & {$[60$} & 90] & {$[90$} & 100] \\
\hline & $\mathrm{D}_{3}$ & {$[60$} & 90] & {$[40$} & 50] & {$[60$} & 90] & {$[60$} & 90] & {$[90$} & 100] \\
\hline & $D_{4}$ & {$[50$} & 60] & {$[50$} & 60] & {$[60$} & 90] & {$[60$} & 90] & {$[90$} & 100] \\
\hline \multirow{4}{*}{ C } & $D_{1}$ & {$[90$} & 100] & {$[90$} & $100]$ & {$[50$} & 60] & {$[60$} & 90] & {$[60$} & 90] \\
\hline & $D_{2}$ & [90 & 100] & {$[60$} & 90] & {$[50$} & 60] & {$[90$} & $100]$ & {$[60$} & 90] \\
\hline & $D_{3}$ & {$[60$} & 90] & {$[50$} & 60] & {$[40$} & 50] & {$[90$} & $100]$ & {$[50$} & $60]$ \\
\hline & $D_{4}$ & {$[60$} & 90] & {$[60$} & 90] & {$[60$} & 90] & [90 & $100]$ & {$[60$} & 90] \\
\hline
\end{tabular}

İkinci bölümde açıklanan gri sayı matematiksel işlemleri ve ortalama durulaştırma yöntemi kullanılarak karar vericilerin yapmış olduğu değerlendirmeler durulaştırılmış ve Tablo 7'deki değerler elde edilmiştir.

Tablo 7: Durulaştırılmış Değerler

\begin{tabular}{|c|c|c|c|c|c|}
\hline & $\mathrm{A}_{1}$ & $\mathrm{~A}_{2}$ & $\mathrm{~A}_{3}$ & $\mathrm{~A}_{4}$ & $\mathrm{~A}_{5}$ \\
\hline $\mathrm{C}_{1}$ & 80 & 77,5 & 80 & 75 & 70 \\
\hline $\mathrm{C}_{2}$ & 80 & 86,25 & 85 & 68,75 & 55 \\
\hline $\mathrm{C}_{3}$ & 57,5 & 58,75 & 62,5 & 73,75 & 85 \\
\hline $\mathrm{C}_{4}$ & 85 & 80 & 75 & 67,5 & 57,5 \\
\hline
\end{tabular}

Adayların $C_{5^{\prime}} C_{6^{\prime}} C_{7}$ ve $C_{8}$ objektif kriterlerinegöre değerlendirme sonuçları ise Tablo 8'de gösterildiği gibidir.

Tablo 8: Objektif Kriterlere Göre Adayların Değerlendirmesi

\begin{tabular}{|c|c|c|c|c|c|}
\hline & $\mathrm{A}_{1}$ & $\mathrm{~A}_{2}$ & $\mathrm{~A}_{3}$ & $\mathrm{~A}_{4}$ & $\mathrm{~A}_{5}$ \\
\hline $\mathrm{C}_{5}$ & 2 & 4 & 0 & 5 & 3 \\
\hline $\mathrm{C}_{6}$ & 75 & 81 & 80 & 90 & 79 \\
\hline $\mathrm{C}_{7}$ & 83 & 90 & 95 & 88 & 82 \\
\hline $\mathrm{C}_{8}$ & 60 & 45 & 20 & 85 & 70 \\
\hline
\end{tabular}

Değerlendirmede kullanılan kriterlerin yapısı incelendiğinde hepsinin fayda tarzı kriterler olduğu görülmektedir. Referans seri başvuran adaylar arasından her bir kriter için en yüksek değer seçilerek oluşturulmuştur. Bu duruma göre oluşturulan referans serisi aşağıda gösterildiği gibidir.

$$
X_{0}=\{80,86.25,85,85,5,90,95,85\}
$$

Incelenen seriler farklı ölçü birimlerine sahip veriler içerdiğinden bu seriler arasında karşılaştırma yapabilmek için Eșitlik (2)'de açıklanan daha büyük daha iyi durumunda normalizasyon yöntemi kullanılmıştır. Alternatiflerin her bir kriter için aldığı normalize edilmiş değerler Tablo 9'da, Esşitlik (5) kullanılarak hesaplanan gri ilişki katsayıları Tablo 10'da sunulmuştur.

Tablo 9: Normalize Edilmiş Değerler

\begin{tabular}{|l|c|c|c|c|c|c|}
\hline & $\mathrm{A}_{1}$ & $\mathrm{~A}_{2}$ & $\mathrm{~A}_{3}$ & $\mathrm{~A}_{4}$ & $\mathrm{~A}_{5}$ & $\mathrm{X}_{0}$ \\
\hline $\mathrm{C}_{1}$ & 1.00 & 0.75 & 1.00 & 0,50 & 0.00 & 1.00 \\
\hline $\mathrm{C}_{2}$ & 0.80 & 1.00 & 0.96 & 0.44 & 0.00 & 1.00 \\
\hline $\mathrm{C}_{3}$ & 0.00 & 0.04 & 0.18 & 0.59 & 1.00 & 1.00 \\
\hline $\mathrm{C}_{4}$ & 1.00 & 0.81 & 0.63 & 0.36 & 0.00 & 1.00 \\
\hline $\mathrm{C}_{5}$ & 0.40 & 0.80 & 0.00 & 1.00 & 0.60 & 1.00 \\
\hline $\mathrm{C}_{6}$ & 0.00 & 0.40 & 0.33 & 1.00 & 0.26 & 1.00 \\
\hline $\mathrm{C}_{7}$ & 0.07 & 0.61 & 1.00 & 0.46 & 0.00 & 1.00 \\
\hline $\mathrm{C}_{8}$ & 0.61 & 0.38 & 0.00 & 1.00 & 0.76 & 1.00 \\
\hline
\end{tabular}

Tablo 10: Gri iliş̧ki Katsayıları

\begin{tabular}{|l|c|c|c|c|c|}
\hline & $\mathrm{A}_{1}$ & $\mathrm{~A}_{2}$ & $\mathrm{~A}_{3}$ & $\mathrm{~A}_{4}$ & $\mathrm{~A}_{5}$ \\
\hline $\mathrm{C}_{1}$ & 1.00 & 0.66 & 1.00 & 0.50 & 0.33 \\
\hline $\mathrm{C}_{2}$ & 0.71 & 1.00 & 0.92 & 0.47 & 0.33 \\
\hline $\mathrm{C}_{3}$ & 0.33 & 0.34 & 0.37 & 0.55 & 1.00 \\
\hline $\mathrm{C}_{4}$ & 1.00 & 0.73 & 0.57 & 0.44 & 0.33 \\
\hline $\mathrm{C}_{5}$ & 0.45 & 0.71 & 0.33 & 1.00 & 0.55 \\
\hline $\mathrm{C}_{6}$ & 0.33 & 0.45 & 0.42 & 1.00 & 0.40 \\
\hline $\mathrm{C}_{7}$ & 0.35 & 0.56 & 1.00 & 0.48 & 0.33 \\
\hline $\mathrm{C}_{8}$ & 0.56 & 0.44 & 0.33 & 1.00 & 0.68 \\
\hline
\end{tabular}

Adayların değerlendirilmesinde kullanılan kriterler farklı ağırlık değerlerine sahiptir. Gri ilişski derecelerinin hesaplanabilmesi için ikinci bölümde açıklanan GANP yardımıyla kriter ağırlıklarının hesaplanmasına intiyaç duyulmaktadır. Bu maksatla değerlendirmede kullanılacak sekiz kriter arasındaki iç bağımlılıklar karar vericilerin görüşlerine göre belirlenmiştir. Örneğin eğiticinin anlama ve anlatma yeteneğini $\left(C_{1}\right)$; öğretmenlik deneyimi $\left(C_{5}\right)$, bilimsel yeterliliği $\left(C_{6}\right)$ ve akademik çalışmaları $\left(C_{8}\right)$ etkilemektedir. Diğer kriterlerin iç bağımlılıkları Tablo 11 'de, kriterlerin gri ikili karşılaştırma matrisleri Tablo 12 'de gösterilmiştir.

Tablo 11: Kriterler Arasındaki İç Bağımlılıklar

\begin{tabular}{|c|l|}
\hline Etkilenen Kriter & Etkileyen Kriter \\
\hline $\mathrm{C}_{1}$ & $\mathrm{C}_{5^{\prime}} \mathrm{C}_{6^{\prime}} \mathrm{C}_{8}$ \\
\hline $\mathrm{C}_{2}$ & $\mathrm{C}_{4^{\prime}} \mathrm{C}_{5}$ \\
\hline $\mathrm{C}_{3}$ & $\mathrm{C}_{1^{\prime}} \mathrm{C}_{2^{\prime}} \mathrm{C}_{5^{\prime}} \mathrm{C}_{6}$ \\
\hline $\mathrm{C}_{4}$ & $\mathrm{C}_{1^{\prime}} \mathrm{C}_{2^{\prime}} \mathrm{C}_{3^{\prime}} \mathrm{C}_{6^{\prime}} \mathrm{C}_{8}$ \\
\hline $\mathrm{C}_{5}$ & $\mathrm{C}_{1^{\prime}} \mathrm{C}_{7^{\prime}} \mathrm{C}_{8}$ \\
\hline $\mathrm{C}_{6}$ & $\mathrm{C}_{1^{\prime}} \mathrm{C}_{3^{\prime}} \mathrm{C}_{5^{\prime}} \mathrm{C}_{7^{\prime}} \mathrm{C}_{8}$ \\
\hline $\mathrm{C}_{7}$ & $\mathrm{C}_{1^{\prime}} \mathrm{C}_{8}$ \\
\hline $\mathrm{C}_{8}$ & $\mathrm{C}_{1^{\prime}} \mathrm{C}_{6^{\prime}} \mathrm{C}_{7}$ \\
\hline
\end{tabular}


Tablo 12: Kriterlerin İçin Gri İkili Karşılaştırmalar Matrisi

\begin{tabular}{|l|c|c|c|c|c|c|c|c|c|c|c|c|c|c|c|c|}
\hline & \multicolumn{2}{|c|}{$C_{1}$} & \multicolumn{2}{c|}{$C_{2}$} & \multicolumn{2}{c|}{$C_{3}$} & \multicolumn{2}{c|}{$C_{4}$} & \multicolumn{2}{c|}{$C_{5}$} & \multicolumn{3}{c|}{$C_{6}$} & \multicolumn{2}{c|}{$C_{7}$} & $C_{8}$ \\
\hline$C_{1}$ & {$[1,00$} & $1,00]$ & {$[1,00$} & $3,00]$ & {$[3,00$} & $5,00]$ & {$[1,00$} & $3,00]$ & {$[3,00$} & $5,00]$ & {$[0,33$} & $1,00]$ & {$[5,00$} & $7,00]$ & {$[1,00$} & $3,00]$ \\
\hline$C_{2}$ & {$[0,33$} & $1,00]$ & {$[1,00$} & $1,00]$ & {$[3,00$} & $5,00]$ & {$[1,00$} & $1,00]$ & {$[3,00$} & $5,00]$ & {$[0,33$} & $1,00]$ & {$[5,00$} & $7,00]$ & {$[1,00$} & $3,00]$ \\
\hline$C_{3}$ & {$[0,20$} & $0,33]$ & {$[0,20$} & $0,33]$ & {$[1,00$} & $1,00]$ & {$[1,00$} & $1,00]$ & {$[1,00$} & $3,00]$ & {$[0,20$} & $0,33]$ & {$[1,00$} & $3,00]$ & {$[1,00$} & $3,00]$ \\
\hline$C_{4}$ & {$[0,33$} & $1,00]$ & {$[1,00$} & $1,00]$ & {$[1,00$} & $1,00]$ & {$[1,00$} & $1,00]$ & {$[5,00$} & $7,00]$ & {$[0,14$} & $0,20]$ & {$[3,00$} & $5,00]$ & {$[1,00$} & $3,00]$ \\
\hline$C_{5}$ & {$[0,20$} & $0,33]$ & {$[0,20$} & $0,33]$ & {$[0,33$} & $1,00]$ & {$[0,14$} & $0,20]$ & {$[1,00$} & $1,00]$ & {$[0,20$} & $0,33]$ & {$[1,00$} & $1,00]$ & {$[0,33$} & $1,00]$ \\
\hline$C_{6}$ & {$[1,00$} & $3,00]$ & {$[1,00$} & $3,00]$ & {$[3,00$} & $5,00]$ & {$[5,00$} & $7,00]$ & {$[3,00$} & $5,00]$ & {$[1,00$} & $1,00]$ & {$[5,00$} & $7,00]$ & {$[1,00$} & $3,00]$ \\
\hline$C_{7}$ & {$[0,14$} & $0,20]$ & {$[0,14$} & $0,20]$ & {$[0,33$} & $1,00]$ & {$[0,20$} & $0,33]$ & {$[1,00$} & $1,00]$ & {$[0,14$} & $0,20]$ & {$[1,00$} & $1,00]$ & {$[0,20$} & $0,33]$ \\
\hline$C_{8}$ & {$[0,33$} & $1,00]$ & {$[0,33$} & $1,00]$ & {$[0,33$} & $1,00]$ & {$[0,33$} & $1,00]$ & {$[1,00$} & $3,00]$ & {$[0,33$} & $1,00]$ & {$[3,00$} & $5,00]$ & {$[1,00$} & $1,00]$ \\
\hline
\end{tabular}

Kriterler arasındaki iç bağımlılıkları hesaplamak için benzer şekilde sekiz adet ikili karşılaştırma matrisi oluşturulmuştur. C kriteri için oluşturulan gri iç karşılaştırma matrisi örnek olarak Tablo 13'de gösterilmiştir. Tablo 12 ve Tablo 13 oluşturulurken karar vericilerden subjektif olarak her bir kriterin diğer bir kritere göre önem derecelerini belirlemeleri istenmiştir. Daha sonra Tablo 2 yardımıyla, yapılan subjektif değerlendirmeler gri sayılara dönüştürülmüştür.

Tablo 13: $C_{1}$ Kriteri İçin Gri İç Bağımlııılar Matrisi

\begin{tabular}{|l|l|l|l|l|l|l|}
\hline & \multicolumn{2}{|c|}{$C_{5}$} & \multicolumn{2}{c|}{$C_{6}$} & \multicolumn{2}{c|}{$C_{8}$} \\
\hline$C_{5}$ & {$[1,00$} & $1,00]$ & {$[0,20$} & $0,33]$ & {$[0,33$} & $1,00]$ \\
\hline$C_{6}$ & {$[3,00$} & $5,00]$ & {$[1,00$} & $1,00]$ & {$[3,00$} & $5,00]$ \\
\hline$C_{8}$ & {$[1,00$} & $3,00]$ & {$[0,20$} & $0,33]$ & {$[1,00$} & $1,00]$ \\
\hline
\end{tabular}

Benzer değerlendirmeler diğer kriterler için de yapılmış ve ikinci bölümde detaylı olarak açıklanan GANP yöntemi ile Tablo 14'de gösterilen durulaştırılmış kriter ağırlıkları hesaplanmıştır. Gri sayıların durulaştırılması için ikinci bölümde açıklanan eşit ağırlıklı ortalama durulaştırması kullanılmıştır.

Tablo 14: Durulaştırılmış Kriter Ağırıkları

\begin{tabular}{|c|c|}
\hline Kriterler & Durulaştıııımıs Kriter Ağırlıkları \\
\hline$C_{1}$ & 0,328 \\
\hline$C_{2}$ & 0,062 \\
\hline$C_{3}$ & 0,026 \\
\hline$C_{4}$ & 0,100 \\
\hline$C_{5}$ & 0,072 \\
\hline$C_{6}$ & 0,181 \\
\hline$C_{7}$ & 0,054 \\
\hline$C_{8}$ & 0,177 \\
\hline
\end{tabular}

Elde edilen durulaştırılmış kriter ağırlıkları Eşitlik (10)'da yerine yazılarak Tablo 15'de gösterilen gri ilişki dereceleri hesaplanmıştır. Gri ilişki derecelerinin birbirlerine bu kadar yakın değerler alması alternatifler arasında bariz farklılıkların bulunmamasından kaynaklanmaktadır.
Tablo 15: Gri İlişki Dereceleri

\begin{tabular}{|c|c|c|c|c|c|}
\hline & $\mathrm{A}_{1}$ & $\mathrm{~A}_{2}$ & $\mathrm{~A}_{3}$ & $\mathrm{~A}_{4}$ & $\mathrm{~A}_{5}$ \\
\hline$\gamma\left(\mathrm{X}_{0}, \mathrm{X}_{\mathrm{i}}\right)$ & 0,693 & 0,607 & 0,668 & 0,708 & 0,442 \\
\hline
\end{tabular}

İki seri arasındaki gri ilişki derecesi ne kadar yüksekse o seriler arasındaki geometrik benzerlik o denli yüksek demektir. Ulaşılan sonuçlar incelendiğinde referans seriye geometrik olarak en yakın serinin 0,708 gri ilişki derecesi ile $A_{4}$ serisi olduğu görülmektedir. Bu sonuç yapılan değerlendirmeler ışığında en iyi adayın dört numaralı aday olduğunu belirtmektedir. Adayların en iyiden en kötüye sıralanması ise aşağıda gösterildiği gibi gerçekleşmiştir. Bu sıra aynı zamanda karar vericilerin tercih sıralamasını göstermektedir.

$$
A_{4}>A_{1}>A_{3}>A_{2}>A_{5}
$$

ÇKKV yöntemlerinde farklı kriter ağırlıklarının farklı sonuçlar doğurması olası bir durumdur. $\mathrm{Bu}$ amaçla karar vericilerden kriter ağırlıklarının hesaplanması için yapmış oldukları değerlendirmeleri kendilerince makul sınırlar dahilinde değiştirmeleri istenmiştir. Değişik kriter ağırlıkları için beş farklı senaryo denenmiş ve bu senaryolara karşılık gelen gri ilişki dereceleri ve alternatiflerin sıralaması incelenmiştir. Tablo $16^{\prime} \mathrm{da}$ beş farklı senaryoda kullanılan durulaştırılmış kriter ağırlıkları, Tablo 17 'de ise bu kriter ağırlıklarına karşılık gelen gri ilişki dereceleri ve alternatiflerin sıralamaları gösterilmiştir. Tablo 17'deki veriler incelendiğinde $A_{4}$ alternatifinin iki farklı senaryoda en iyi bir diğer senaryoda ise ikinci en iyi alternatif olduğu görülmektedir. $A_{3}$ alternatifi ise üç farklı senaryoda en iyi, bir senaryoda ise ikinci en iyi alternatif konumundadır. Diğer alternatifler hiçbir senaryoda en iyi alternatif olamamışlardır. Bu durum yapılacak seçimde $A_{4}$ veya $A_{3}$ alternatifinin seçilmesinin uygun olacağı anlamına gelmektedir. 
Tablo 16: Farklı Senaryolar İ̧̧in Durulaştırılmış Kriter Ağırlıkları

\begin{tabular}{|l|c|c|c|c|c|c|c|c|}
\hline \multicolumn{1}{|c|}{ Kriter } & $C_{1}$ & $C_{2}$ & $C_{3}$ & $C_{4}$ & $C_{5}$ & $C_{6}$ & $C_{7}$ & $C_{8}$ \\
\hline Senaryo_I & 0,15 & 0,25 & 0,05 & 0,05 & 0,05 & 0,2 & 0,15 & 0,1 \\
\hline Senaryo_I & 0,15 & 0,15 & 0,05 & 0,05 & 0,2 & 0,2 & 0,1 & 0,1 \\
\hline Senaryo_III & 0,12 & 0,16 & 0,04 & 0,2 & 0,04 & 0,21 & 0,12 & 0,11 \\
\hline Senaryo_IV & 0,2 & 0,2 & 0,1 & 0,1 & 0,05 & 0,15 & 0,1 & 0,1 \\
\hline Senaryo_V & 0,15 & 0,18 & 0,1 & 0,12 & 0,1 & 0,15 & 0,15 & 0,05 \\
\hline
\end{tabular}

Tablo 17: Farklı Senaryolar İçin Gri iliş̧ki Dereceleri

\begin{tabular}{|c|c|c|c|c|c|c|}
\hline & $\gamma\left(X_{0^{\prime}}, X_{i}\right)$ & $A_{1}$ & $\mathrm{~A}_{2}$ & $\mathrm{~A}_{3}$ & $\mathrm{~A}_{4}$ & $\mathrm{~A}_{5}$ \\
\hline \multirow{2}{*}{ Senaryo_I } & Derece & 0,594 & 0,660 & 0,715 & 0,665 & 0,427 \\
\hline & Sira & 4 & 3 & 1 & 2 & 5 \\
\hline \multirow{2}{*}{ Senaryo_I } & Derece & 0,573 & 0,639 & 0,623 & 0,743 & 0,461 \\
\hline & Sira & 4 & 2 & 3 & 1 & 5 \\
\hline \multirow{2}{*}{ Senaryo_III } & Derece & 0,640 & 0,642 & 0,659 & 0,663 & 0,423 \\
\hline & Sira & 3 & 4 & 2 & 1 & 5 \\
\hline \multirow{2}{*}{ Senaryo_IV } & Derece & 0,641 & 0,646 & 0,695 & 0,641 & 0,457 \\
\hline & Sira & $3-4$ & 2 & 1 & $3-4$ & 5 \\
\hline \multirow{2}{*}{ Senaryo_V } & Derece & 0,608 & 0,649 & 0,688 & 0,640 & 0,451 \\
\hline & Sira & $3-4$ & 2 & 1 & $3-4$ & 5 \\
\hline
\end{tabular}

Elde edilen sonuçları karşılaştırmak amacıyla aynı problem TOPSIS, ANP ve ELECTRE yöntemleri kullanılarak çözülmüştür. Tablo 18, adayların TOPSiS yöntemine göre pozitif ideal çözümden $\left(S_{i}^{*}\right)$ ve negatif ideal çözümden $\left(S_{i}^{-}\right)$uzaklık değerleri ile yakınlık katsayıları $\left(C_{i}^{*}\right)$ ve sıralamalarını göstermektedir. Adaylar diğer ÇKKV yöntemlerine göre değerlendirilmesi ile elde edilen sonuçlar ise karşılaştırmalı olarak Tablo 19'de sunulmuştur.

Tablo 18: TOPSiS Çözümü

\begin{tabular}{|c|c|c|c|c|}
\hline \multirow{2}{*}{} & \multicolumn{2}{|c|}{ Uzaklık Değerleri } & \multicolumn{2}{c|}{ Sıralama } \\
\cline { 2 - 5 } & $\mathrm{S}_{\mathrm{i}}^{*}$ & $\mathrm{~S}_{\mathrm{i}}$ & $\mathrm{C}_{\mathrm{i}}^{*}$ & Sıra \\
\hline $\mathrm{A}_{1}$ & 0,7011 & 0,6639 & 0,486 & 3 \\
\hline $\mathrm{A}_{2}$ & 0,2314 & 1,0742 & 0,823 & 2 \\
\hline $\mathrm{A}_{3}$ & 1,1593 & 0,1170 & 0,092 & 5 \\
\hline $\mathrm{A}_{4}$ & 0,1836 & 1,0661 & 0,853 & 1 \\
\hline $\mathrm{A}_{5}$ & 0,8517 & 0,3367 & 0,283 & 4 \\
\hline
\end{tabular}

Tablo 19: Karşılaştırmalı Sonuçlar

\begin{tabular}{|c|c|c|c|}
\hline Sıralama & TOPSIS & ANP & ELECTRE \\
\hline 1 & $\mathrm{~A}_{4}$ & $\mathrm{~A}_{2}$ & $\mathrm{~A}_{1}$ \\
\hline 2 & $\mathrm{~A}_{2}$ & $\mathrm{~A}_{4}$ & $\mathrm{~A}_{4}$ \\
\hline 3 & $\mathrm{~A}_{1}$ & $\mathrm{~A}_{5}$ & $\mathrm{~A}_{5}$ \\
\hline 4 & $\mathrm{~A}_{5}$ & $\mathrm{~A}_{1}$ & $\mathrm{~A}_{2}$ \\
\hline 5 & $\mathrm{~A}_{3}$ & $\mathrm{~A}_{3}$ & $\mathrm{~A}_{3}$ \\
\hline
\end{tabular}

Elde edilen sonuçlar incelendiğinde $\mathrm{A}_{4}$ alternatifinin, TOPSIS yöntemine göre yapılan sıralamada birinci, ANP ve ELECTRE yöntemlerine göre yapılan sıralamada ise ikinci sırada yer aldığı görülmektedir. $A_{3}$ alternatifi ise tüm yöntemlerde en kötü alternatif olmuştur. Bu sonuçlara dayanarak her ne kadar farklı yöntemler için farklı sıralamalar elde edilse de $\mathrm{A}_{4}$ alternatifinin diğerlerine göre daha iyi bir alternatif olduğunu ve yapılacak seçimde bu alternatife öncelik verilmesi gerektiğini söylemek mümkündür.

\section{SONUÇ VE ÖNERILER}

Bu çalışmada hem subjektif hem de objektif kriterlerin yer aldığı personel seçim problemlerinin çözümü için gri sistem teori tabanlı bütünleşik bir yaklaşım önerilmiştir. Kriter ağırlıklarının hesaplanmasında GANP kullanılmıştır. GANP'nin ANP' den farkı ikili karşılaştırmalar sürecinde gri sayıların kullanılmasına izin vermesidir. Bu sayede kesin olmayan yargıları geleneksel ANP'de olduğu gibi tek bir sayı ile göstermek yerine uygun bir aralıkla temsil etmek mümkün olmaktadır. En uygun adayın belirlenmesinde ise GiA'dan yararlanılmıştır. GIA referans seri ile karşılaştırılan serilerin geometrik benzerliklerini ortaya çıkartmaya yönelik etkili bir yöntemdir. Referans seriye benzerlik ne kadar fazla olursa alternatifin tercih edilirliği o denli yüksek olmaktadır. Elde edilen sonuçları test etmek maksadıyla aynı problem TOPSIS, ANP ve ELECTRE yöntemleri kullanılarak çözülmüştür. Ulaşılan sonuçlar dört yöntemin de en iyi aday konusunda hemenhemen uzlaşı içerisinde olduklarını göstermiştir.

Bu çalışma ile personel seçimi problemlerinin çözümünde gri sistem teori tabanlı yaklaşımların başarı ile uygulanabileceği örnek bir uygulama ile gösterilmeye çalışılmıştır. Personel seçimi için önerilen bütünleşik model; ürün/araç seçimi, tedarikçi seçimi, ulaşım politikalarının belirlenmesi, enerji kaynaklarının önceliklendirilmesi gibi birçok ÇKKV probleminde uygulanabileceği değerlendirilmektedir. 


\section{KAYNAKLAR}

Ayub, M., Kabir, J. ve Alam, G.R. (2009) "Personnel Selection Method Using Analytic Network Process (ANP) and Fuzzy Concept" 12th International Conference on Computerand Information Technology, 373-377.

Chen, M.F. ve Tzeng, G.H. (2004) "Combining GreyRelationand Topsis Conceptsfor Selecting an Expatriate Host Country" Mathematical and Computer Modelling, 40:1473-1490.

Chen, C.H. ve Tzeng, G.H. (2011) "Assessment Model for Improving Educational Curriculum Materials Based on The DANP Techniquewith Grey Relational Analysis" IJISLM, 6(2): 23-36.

Chen, C.T., Hwang, Y.C. ve Hung, W.Z. (2009) "Applying Multiple Linguistic PROMETHEE Method for Personnel Evaluation and Selection" IEEE International Conference, 1312-1316.

Deng, J.L. (1982) "Control Problems of Grey Systems” Systems\& Control Letters, 5: 288-294.

Deng, J.L. (1996) "Difference among Grey, Probability, Fuzzy" Journal of Grey System, 3: 256-262.

Dursun, M. ve Karsak, E.E. (2010) “A Fuzzy MCDM Approachfor Personnel Selection" Expert Systemswith Applications, 37:4324-4330.

Feng, C.M. ve Wang,R.T. (2000) "Performance Evaluation for Airlines Including The Consideration Financial Ratios" Journal of Air Transport Management, 6:133-142.

Gibney, R. ve Shang, J. (2007) “Decision-Making in Academia: A Case of The Dean Selection Process" Mathematical and Computer Modelling, 46:1030-1040.

Goyal, S. ve Grover, S. (2012) "Applying Fuzzy Grey Relational Analysis for Ranking The Advanced Manufacturing Systems"Grey Systems: Theoryand Application, 2(2):284-298.

Güngör, Z., Serhadlığlu, G. ve Kesen, S.E. (2009) "A fuzzy AHP Approach to Personnel Selection" Applied Soft Computing, 9:641-646.

Hsu, P.F. (2012) "Selection Model Based on ANP and GRA for Independent Media Agencies" Quality \& Quantity, 46(1): 1-17.

Jadidi, O., Hong, T.S., Firouzi, F. ve Yusuf, R.M. (2008) "An Optimal Grey Based Approach Based on TOPSIS Concepts for Supplier Selection Problem" International Journal of Management Scienceand Engineering Management, 4(2):104-117.

Jharkharia, S. ve Shankar, R. (2007) "Selection of Logistics Service Provider: An Analytic Network Process (ANP) Approach" Omega, 35:274-289.
Kabak, M., Burmaoğlu, S. ve Kazancoğlu, Y. (2012)

"A Fuzzy Hybrid MCDM Approach for Professional Selection" Expert Systems with Applications, 39(3):3516-3525.

Kelemenis, A.M. ve Askounis, D. (2010) "A New TOPSIS-Based Multi-Criteria Approach to Personnel Selection" Expert Systemswith Applications, 37(7):4999-5008.

Kose, E., Temiz, I. ve Erol, S.(2011)“Grey System Approach for Economic Order Quantity Models Under Uncertainty" The Journal of Grey System, 1:71-82.

Lazarevic-Petrovic, S. (2001) "Personnel Selection FuzzyModel"International Transactions in Operational Research, 8:89-105.

Li, G.D.,Yamaguchi, D. ve Nagai,M. (2007) "A Grey-Based Decision-Making Approachto The Supplier Selection Problem" Mathematical and Computer Modeling, 46:537-581.

Liu, S. ve Lin,Y. (2006) “Grey Information: Theoryand Practical Applications” Springer,11-21.

Mohammad, Y.N., Vahid,B. ve Majid, A. (2011) "Planning a Model for Supplier Selection with AHP and Grey Systems Theory" Business and Management Review, 1(7):09-19.

Mohanty, R.P., Agarwal, R., Choudhury, A.K. ve Tiwari, M.K. (2005) "A Fuzzy ANP Based Approach to R\&D Project Selection: A Case Study” International Journal of Production Research, 43(24):5199-5216.

Onut, S., Kara, S.S. ve Isık, E. (2009) "Long Term Supplier Selection Using a Combined Fuzzy MCDM Approach: A Case Studyfor a Telecommunication Company" Expert Systems with Applications, 36:38873895.

Pramanik, S. ve Mukhopadhyaya, D. (2011) "GreyRelational Analysis Based IntuitionisticFuzzy Multi-Criteria Group Decision-Making Approach for Teacher Selection in Higher Education" International Journal of Computer Applications, 34(10):21-29.

Saaty, T.L. (1985) TheAnalyticHierarchyProcess, New York, McGraw-Hill.

Saaty, T.L. (1996) Decision Making with Dependenceand Feedback: The Analytic Network Process, Pittsburgh, RWS Publications.

Saaty, T.L. (2000) Fundamentals of cision Makingand Priority Theory with Analytic Hierarchy Process, Pittsburg, RWS Publications.

Song, Q. ve Jamalipour, A. (2005) "An AdaptiveQuality-of-Service Network Selection Mechanism for Heterogeneous Mobile Networks" Wireless Communications and Mobile Computing, 5: 697-708. 
Song, Q., Shepperd, M. ve Mair, C. (2005) "Using Grey Relational Analysis to Predict Software Effortwith Small Data Sets" 11th IEEE International Software Metrics Symposium, 10-35.

Wang, D. (2009) "Extension of TOPSIS Methodfor R\& D Personnel Selection Problem with Interval Grey Number" International conference on IEEE IEEM, 1-4.

Wen, K.L. (2004) Grey Systems: Modeling and Prediction, TucsonUSA, Yang Sky ScientificPress.

Wu, H.H. (2002) "A Comparative Study of Using Grey Relational Analysis in Multiple AttributeDecisionMaking Problems" Quality Engineering, 15(2): 209-217.
Wu, Q. ve Luyan, L. (2012) "Research on Investment Decision-Making of Construction Engineering Projects Based on the Grey Relation Grade" Advanced Science Letters, 15(1): 407-409.

Yeh, M.F. ve Lu, H.C. (2000) "Evaluating Weapon Systems Based on GreyRelational Analyisand Fuzzy Arithmetic Operations" Journal of the Chinese Institute of Engineers, 23(2):211-221.

Zhang, S.F. ve Liu, S.Y. (2011) "A GRABasedIntuitionistic Fuzzy Multi-Criteria Group DecisionMaking Method for Personnel Selection" Expert Systems with Applications, 38: 11401-11405. 
